\title{
The Experiences of Three Different User Groups Using Personally Controlled Health Record for Multidisciplinary Care Team
}

\author{
Nadia Ghandour \\ Senior Analyst, Royal Brompton and Harefield NHS Foundation Trust \\ United Kingdom \\ nadia.ghan@gmail.com
}

\begin{abstract}
Ahmad Ghandour
Associate Professor

College of Business

Al Ain University of Science \& Technology

Abu Dhabi / UAE
\end{abstract}

\section{Abstract}

Personally Controlled Health Records (PCHR) are patient-centric tools which allow individuals to own, manage, access and share their health information online from anywhere, at any time. Patient-centric tools have received considerable interest and investment in recent years worldwide. These tools are thought to have the potential to increase individuals' selfmanagement and involvement in their own health, as well as improve healthcare efficiency and delivery. The aim of this study is to report and analyse the experiences of three different user groups using PCHR for Multidisciplinary Care Team (MDCT) including the advantages, disadvantages, barriers and obstacles, and the current state of PCHR. In order to achieve the aim of this study, sixteen interviews with key informants from three different user groups were conducted in Dunedin, New Zealand. Interviews were transcribed and analysed with thematic analysis. The key findings of this research showed that those who can benefit the most from PCHRs are the least able to use it. It suits those who have basic knowledge about computers and the internet and those who can afford to use them. PCHR is also best suited for individuals who are motivated about their health despite their health condition. However, more research is needed in the future with a larger sample, an easier to use PCHR, different population other than community health workers, patients with different chronic illnesses, and healthy patients. This research can be used as a basis and tested in future research on PCHR adoption.

Keywords: PCHR, EHR, The Diary, Health Informatics, MDCT

\section{Introduction}

Information Technology is playing a vital role in attempts to improve healthcare systems and address current challenges in healthcare delivery. With the rise of chronic diseases and the major cost consumed on those with long-term conditions, there is an even greater need to find solutions that improve health care systems significantly. The emphasis on patient-centric and integrated healthcare systems is worldwide. Patient-centric tools have the potential to improve patients' satisfaction with their health, their clinical outcomes, and medical services efficiency. In recent years, personally controlled health records (PCHRs) in particular have sparked significant interest in healthcare systems (Pagliari, Detmer, \& Singleton, 2007; Tang, Ash, 
Bates, Overhage, \& Sands, 2006). Other terms have also been used in the literature and in organisations such as personal health records (PHRs) and electronic health diary (EHD) (Lober et al., 2006). For this current research, the term PCHR will be used to fit any system that is webbased and allows patients to access, control, manage and track their own health.

In the past few years, there has been a dramatic increase in the number of patients seeking health information online, on social media sites and other web-based resources (Archer, Fevrier-Thomas, Lokker, McKibbon, \& Straus, 2011; Beard, Schein, Morra, Wilson, \& Keelan, 2012). Modern countries are striving to improve the way in which health services are delivered and managed. They are finding an effective way which will reduce the death rate among those with long-term conditions as well as reducing the cost. One approach is a person-centric shared plan which involves all health professionals that have a role in the patient's care working to a common care plan and sharing information between them. The objective of this person-centric approach is to put the person at the centre of their care and create a collaborative/integrated environment for those with long-term conditions to manage their conditions at home, and for their caregivers who play a part in managing their conditions. This approach will get patients involved in managing their own health, improve efficiency of the usage of healthcare resources, improve time saving and safety, and improve patients' relationships with their health providers. Shared care planning allows patients access to their personal health information, treatment and follow-up plans, receive their laboratory results, and communicate electronically with their health providers.

Physicians hold health information on their patients and spend a considerable amount of time during an office visit to provide their patients with education and instructions regarding their health (Tang et al., 2003). At the same time, there is a limited time for each visit, therefore patients are not always satisfied because they may not have enough time to get the information they need. Also, being under time pressure could mean that they might forget to ask questions, or it could result in them leaving without understanding (Levinson, Lesser, \& Epstein, 2010; Tang et al., 2003). For example, according to a survey of patients conducted in 2004 by the Commonwealth Fund in five countries (Australia, Canada, New Zealand, the United Kingdom, and the United States); respondents across all countries reported that their doctors are sometimes, rarely or never able to communicate well with patients, tell them about treatment plans or get them involved in making care decisions (Ball, Carla Smith, \& Bakalar, 2007; Schoen et al., 2004).

Patients need to be more engaged as partners in their health and their knowledge about their health needs to be satisfied (Tang et al., 2003). Electronic health records (EHRs) are not typically shared with patients (Beard et al., 2012). Thus, better methods of providing information to patients are needed (Beard et al., 2012; Zickmund et al., 2008). Personally controlled health records (PCHRs) represent an important and increasingly accepted health information technology to support self-management and patient-centred care (Krist \& Woolf, 2011).

Moreover, the care of patients nowadays usually involves multidisciplinary care teams (MDCTs) that all require to share and discuss information about patients. Those MDCTs are lacking communication and facing a major issue in delivering healthcare efficiently. There is a gap in communication between healthcare providers across primary care providers in the community and the hospital-based care providers. Community healthcare providers are 
struggling in obtaining the information they need about their patients, thus, facing issues in delivering quality care (Coiera, 2006).

Therefore, there is an increasing need for a system that bridges the gap between the complex MDCTs as well as the patients and puts them all on the same page. It is also very important to make health information available at an efficient time for those who need it in order to ensure success of care (Fichman, Robert 2011).

This research area is still at its inception and the literature is growing towards contributing valuable outcomes for the diffusion of PCHR. No studies have looked specifically at the use of PCHR by community groups nor at the use of PCHR by different user groups. For the successful use of PCHR by different groups, it is important to understand their views and the experiences of the use of this new phenomenon. It is important to learn:

1. If PCHR will improve workflow and efficiency of current healthcare systems as has been reported in the literature.

2. The advantages and disadvantages of using the PCHR based on the experiences of those groups who used it.

3. User's concerns about PCHR including privacy concerns.

4. Identify the group of people that will most likely use and benefit from the PCHR.

5. Learn about the current state of PCHR.

This research will help understand the experiences of different user groups on how PCHR will possibly benefit them, what are the disadvantages they experienced with using the new phenomenon, who is the best user for PCHR from their point of view, what are their concerns on PCHR and if they view PCHR as a tool that will improve the efficiency of healthcare systems. The aim of this current research is to report and analyse the experiences of three different user groups using PCHR for MDCT.

This article is structured as follows. First, PCHR is reviewed with regards to its benefits, barriers adoption and current state, followed by the methodology of the study. Subsequently, Results and analysis section is presented followed by discussion. Finally, a conclusion ends the study.

\section{Personally Controlled Health Record (PCHR)}

A Personally Controlled Health Record (PCHR) is a special type or a sub-set of personal health records (PHRs) distinguished by giving users more control over the access to and the content of their records (Bourgeois, Taylor, Emans, Nigrin, \& Mandl, 2008; Mandl, Simons, Crawford, \& Abbett, 2007; Weitzman, Kaci, \& Mandl, 2009). Markel Foundation (2003) defined PHR in their "connecting for health" report as:

"An electronic application through which individuals can access, manage and share their health information, and that of others for whom they are authorized, in a private, secure, and confidential environment." (p.14)

In PCHRs, patients do not only manage their health-related information, but they also own them. Patients populate their records, decide on the data sources, control who is allowed to view/edit their records, and what to view/edit exactly (Mandl et al., 2007; Weitzman et al., 2009). 
It is generally assumed that increasing individuals' control over their medical records will improve health, self-care preparation and reduce medication errors (Mandl et al., 2007; Weitzman et al., 2009). PCHRs and PHRs include the same information; they both allow individuals to capture, access, and manage their own health information. They can have a lifelong summary of their health information in one convenient place. A typical PCHR/PHR captures information such as: allergies, medical conditions, medication, medical treatments, immunisation, and test results (Tang et al., 2006; Weitzman et al., 2009; Wynia, Torres, \& Lemieux, 2011).

There are several models of PCHRs that have been described in the literature, but most are variations of tethered (EHR-based) systems and untethered (stand-alone) systems (Archer et al., 2011; D. Kaelber \& Pan, 2008; Patel et al., 2011).

Electronic Health Record (EHR) refers to a full health record for a patient that is primarily held by a healthcare provider in electronic form (Kim et al., 2009; Shaw, Kulkarni, \& Mador, 2011). Over the past few years, the adoption of EHRs has been incredibly widespread. The EHR maintained by clinicians is a medico-legal requirement for clinicians; hard copy in the first instance but increasingly becoming electronic.

EHRs are considered distinct from PCHRs, due to that fact that EHRs are usually controlled by health providers and patients are seldom able to easily access these records and consequently are unable to fully engage in the management of their own health plans without access to the electronic information (Hillestad et al., 2005). Accessibility has been limited due to many constraints, such as; legal, ethical, logistical and technological issues. EHR is a term that is sometimes used interchangeably with the term "Electronic Patient Record" and "Electronic Medical Record" (EMR) ${ }^{1}$, although EMR could refer to hospital only medical records. An EHR-based system could be tethered to a provider's electronic health record (EHR) and might include data from several sources such as; appointment systems, laboratories, pharmacies, health insurers and other healthcare entities (Patel et al., 2011). While a stand-alone system could be completely free-standing and include data entered directly from patients, tethered system usually includes data from both self-entered and the electronic health record (EHR) (Anoshiravani et al., 2011; Patel et al., 2011).

According to Archer et al. (2011) a tethered PCHR can convey to the patient much more than a stand-alone PCHR; it enables patients to gather their fragmented health information in one place. Also, integrating PCHRs with EHRs appear to be critical for the successful use of PCHRs (Archer et al., 2011; Detmer, Bloomrosen, Raymond, \& Tang, 2008; Kim et al., 2009; Tang et al., 2006).

Table 1 below shows a summary of PCHR's characteristics which were collected from the literature in comparison to an EHR.

1 https://www.ama-assn.org/ama/pub/physician-resources/health-information-technology/health-itbasics/emrs-ehrs.page 


\begin{tabular}{|l|l|l|}
\hline Access & \multicolumn{1}{|c|}{ PCHR } & \multicolumn{1}{c|}{ EHR } \\
\hline Availability & $\begin{array}{l}\text { Patients can choose who accesses } \\
\text { their information }\end{array}$ & $\begin{array}{l}\text { Patients do not have access to or } \\
\text { control over their information }\end{array}$ \\
\hline Control & $\begin{array}{l}\text { Available for patients from } \\
\text { anywhere at anytime }\end{array}$ & $\begin{array}{l}\text { Only available for healthcare } \\
\text { providers, and can only be accessed } \\
\text { on site }\end{array}$ \\
\hline Information Source & $\begin{array}{l}\text { High patient control } \\
\text { be from both patients and care } \\
\text { providers if the PCHR was } \\
\text { tethered }\end{array}$ & No patient control \\
\hline Ownership & Patients & Healthcare providers \\
\hline Services accessibility & $\begin{array}{l}\text { Flexible access to test results and } \\
\text { appointments if available }\end{array}$ & Not flexible for patients \\
\hline Transparency & $\begin{array}{l}\text { Clear about who edited or } \\
\text { accessed what information }\end{array}$ & Usually not transparent \\
\hline
\end{tabular}

Table 1: PCHR vs. EHR

\subsection{PCHR Adoption:}

While PCHRs have great potential to provide benefits not only for individuals, but for health professionals and health providers as well (Blake \& Kerr, 2010; Detmer et al., 2008; Tang et al., 2006), the supporting evidence of clinical benefits and other specific benefits for PCHRs adoption remains limited (D. Kaelber \& Pan, 2008; Patel et al., 2011; Tang et al., 2006; Tenforde, Jain, \& Hickner, 2011). The following are the benefits and the barriers of adopting PCHRs retrieved from the existing literature:

\subsubsection{Benefits of Adopting PCHRs:}

For individuals, PCHRs offer various potential benefits (Blake \& Kerr, 2010; Tang et al., 2006). Generally, patients' involvement in their care seems to save time, improve care and safety as well as decrease cost (Bourgeois et al., 2008; Greenhalgh, Hinder, Stramer, Bratan, \& Russell, 2010; Hiller, McMullen, Chumney, \& Baumer, 2011). PCHRs have the potential to improve the quality of care and change the way care is delivered to patients, and deliver better health outcomes (Blake \& Kerr, 2010; Caligtan \& Dykes, 2011; D. Kaelber \& Pan, 2008).

Table 2 below represents a summary of the main potential benefits of the PCHR which were reported in the literature. 


\begin{tabular}{|c|l|l|}
\hline 1 & Delivering better health outcomes & (Caligtan \& Dykes, 2011; D. Kaelber \& Pan, 2008) \\
\hline 2 & $\begin{array}{l}\text { Empowering patients and getting } \\
\text { them involved in their own health }\end{array}$ & (Ball et al., 2007; Fuji et al., 2012) \\
\hline 3 & Engaging patients with their health & (Caligtan \& Dykes, 2011; Patel et al., 2011). \\
\hline 4 & Enhancing shared decision making & $\begin{array}{l}\text { (Caligtan \& Dykes, 2011; Tang et al., 2006; Wunder, } \\
\text { 2009) }\end{array}$ \\
\hline 5 & $\begin{array}{l}\text { Improving the relationship between } \\
\text { patients and their health professionals }\end{array}$ & $\begin{array}{l}\text { (Archer et al., 2011; D. C. Kaelber, Jha, Johnston, } \\
\text { Middleton, \& Bates, 2008; Patel et al., 2011) }\end{array}$ \\
\hline 6 & $\begin{array}{l}\text { Improving care delivery and health } \\
\text { outcomes }\end{array}$ & (Caligtan \& Dykes, 2011; D. Kaelber \& Pan, 2008) \\
\hline 7 & $\begin{array}{l}\text { Improving memory and concordance } \\
\text { of the patient }\end{array}$ & (Maeder \& Martin-sanchez, 2012) \\
\hline 8 & $\begin{array}{l}\text { Improving clinical decision making } \\
\text { (Caligtan \& Dykes, 2011; Tang et al., 2006; Wunder, } \\
\text { 2009) }\end{array}$ \\
\hline 10 & $\begin{array}{l}\text { Increased patient control/ownership } \\
\text { own health }\end{array}$ & $\begin{array}{l}\text { (Caligtan \& Dykes, 2011; D. Kaelber \& Pan, 2008) } \\
\text { (Chen, Garrido, Chock, Okawa, \& Liang, 2009; Tang } \\
\text { et al., 2006) }\end{array}$ \\
\hline 11 & Increasing patient safety & $\begin{array}{l}\text { Emont (2011); (Heather et al., 2011; Pagliari et al., } \\
\text { 2007) }\end{array}$ \\
\hline 12 & $\begin{array}{l}\text { Making health information accessible } \\
\text { from anywhere at anytime }\end{array}$ & $\begin{array}{l}\text { (Ball et al., 2007; Caligtan \& Dykes, 2011; Fuji et al., } \\
\text { 2012; Greenhalgh et al., 2010; Pagliari et al., 2007; } \\
\text { Patel et al., 2011; Tang et al., 2006) }\end{array}$ \\
\hline 13 & $\begin{array}{l}\text { Reducing burden of care for clinicians } \\
\text { and care providers }\end{array}$ & $\begin{array}{l}\text { (Chen et al., 2009; Greenhalgh et al., 2010; Pagliari et } \\
\text { al., 2007) }\end{array}$ \\
\hline 14 & $\begin{array}{l}\text { (Bourgeois et al., 2008; Dimick, 2008; Greenhalgh et } \\
\text { al., 2010; Heather et al., 2011; Hiller et al., 2011; D. C. } \\
\text { Kaelber et al., 2008; D. Kaelber \& Pan, 2008; Pagliari } \\
\text { et al., 2007; Steinbrook, 2008; Tang et al., 2006) }\end{array}$ \\
\hline
\end{tabular}

Table 2: Potential benefits of PCHRs

\subsubsection{Barriers and Obstacles with Adopting PCHRs:}

Despite the superficial public interest in having PCHRs and the beliefs in its' potential benefits; there are also some possible impediments that have delayed its widespread adoption that have been discussed in the literature (Lober et al., 2006; Tang et al., 2006). Some of these impediments were related to the following major factors; to the healthcare culture and system, technical factors, infrastructure and policy factors, as well as individual-level factors (Detmer et al., 2008; Kahn, Aulakh, \& Bosworth, 2009; Pagliari et al., 2007; Tang et al., 2006).

Individual-level factors include: security and privacy concerns, attitudes and expectations of PCHRs, desired benefits from PCHR, and user characteristics such as; demographic factors, computer and technology literacy and health literacy (Kahn et al., 2009; Tang et al., 2006; Weitzman et al., 2009).

Table 3 below represents a summary of the barriers to adopting PCHRs which were reported in the literature. 


\begin{tabular}{|c|l|l|}
\hline 1 & $\begin{array}{l}\text { Anxieties around security and } \\
\text { confidentiality }\end{array}$ & $\begin{array}{l}\text { (Hoerbst, Kohl, Knaup, \& Ammenwerth, 2010; D. } \\
\text { C. Kaelber et al., 2008; Keselman et al., 2007; Pyper, } \\
\text { Amery, Watson, \& Crook, 2004) }\end{array}$ \\
\hline 2 & Digital divide & $\begin{array}{l}\text { (Detmer et al., 2008; Roblin, Houston, Allison, Joski, } \\
\text { \& Becker, 2009; Sciadas, 2002). Archer et al. (2011; } \\
\text { Patel et al., 2011). Kim et al (2009); (Miah, Hasan, } \\
\text { Hasan, \& Gammack, 2017); }\end{array}$ \\
\hline 3 & $\begin{array}{l}\text { Healthcare cultural and } \\
\text { workflow issues }\end{array}$ & $\begin{array}{l}\text { (Archer et al., 2011; Detmer et al., 2008; Patel et al., } \\
\text { 2011; Weitzman et al., 2009). }\end{array}$ \\
\hline 4 & $\begin{array}{l}\text { Individual characteristics such } \\
\text { as age, health status or } \\
\text { computer literacy }\end{array}$ & $\begin{array}{l}\text { (Lafky \& Horan, 2008; Walker, Ahern, Le, \& } \\
\text { Delbanco, 2009) }\end{array}$ \\
\hline 5 & $\begin{array}{l}\text { Legal concerns } \\
\text { (Detmer et al., 2008; Patel et al., 2011; Tang et al., } \\
\text { 2006). }\end{array}$ \\
\hline 6 & $\begin{array}{l}\text { Technical issues i.e. fragmented } \\
\text { healthcare systems }\end{array}$ & (Kahn et al., 2009; Pagliari et al., 2007) \\
\hline
\end{tabular}

Table 3: Barriers to adopting PCHRs

\subsection{Patients with Chronic IIIness}

Self-managed care tools such as PHRs and PCHRs have large potential to improve healthcare services for patients regardless of their health conditions. However, according to Steinbrook (2008) and DiMarco et al. (2009), patients with chronic illnesses are the users who may benefit the most from PCHRs. Usually people with chronic conditions are on long-term medication or treatment which involves their general practitioner (GP) and at least one other healthcare provider. These people are the most frustrated and the group that interacts with the healthcare systems most frequently (Steinbrook, 2008). Research has estimated that about (40\%) of the general population in a number of developed countries has a chronic condition (DiMarco et al., 2009; Tomlinson et al., 2009). If this percentage of patients were able to manage their own health, it would have a significant effect on producing effective healthcare at lower costs (DiMarco et al., 2009; Tomlinson et al., 2009). Fragmented systems of storing and retrieving these patients' data will impede their optimal care (Tang et al., 2006). Personally controlled health records create strong potential to help those patients with long-term conditions, including mentally ill patients to manage and monitor their clinical care (Emont, 2011; Ennis, Rose, Callard, Denis, \& Wykes, 2011). Furthermore, according to an online survey done by the "Markle Foundation" in 2003, individuals with chronic illnesses and caregivers for elderly parents reported the highest and the most urgent need for PCHRs (Sprague, 2006). Also, according to both Tang et al. (2006) and Pagliari et al. (2007) patients with long term conditions who receive care from multidisciplinary care team (MDCT) are the ones who will benefit the most from PCHRs and are likely to be the most frequent users of it. Despite this great potential of self-management tools to enhance chronic disease care and improve patient outcomes, the evidence to improve the clinical value remains limited (Tenforde et al., 2011).

\subsection{The Current State of the PCHR:}

Several commercial companies around the world have already started to provide services that allow people to organise their personal health information, integrate health records from different providers, and share them with other people, including healthcare professionals (Bourgeois et al., 2008). These services allow more convenient and patient-centred control of 
health records (DiMarco et al., 2009). Recently various PCHR platforms have been launched: Indivo, Microsoft's HealthVault, and the Dossia (Mandl et al., 2007; Weitzman et al., 2009).

In USA for example, "My Health Manager" is a customisable portal that was fully deployed in 2007 by the US health maintenance organisation Kaiser Permanente, and it was linked to the EHR. This Portal allows members to access parts of their centrally held record, including different health information such as diagnoses, laboratory results, previous clinic visits, medication, allergies and immunizations. It also allows patients to email their doctors through a secure connection and schedule appointments (Greenhalgh et al., 2010; Silvestre, Sue, \& Allen, 2009).

Another internet accessible PCHR was introduced around the world and in England particularly was HealthSpace. HealthSpace allows individuals to create accounts to manage their health. People can add information to their accounts such as their blood pressure, and record healthcare appointments on a calendar. Also, individuals may have an advanced account in which they can gain access to their nationally stored medical summary drawn by a general practitioner, book appointments, and exchange emails with their clinician (Greenhalgh et al., 2010).

In Australia, a new programme for Internet-based Person-Controlled Electronic Health Records (P-CEHRs) was recently introduced by the Australian government. The P-CEHR plan is that from July 2012 those Australian patients, who wish to, will have a secure portal through which they can access their health information that is stored on their different healthcare providers' systems. This P-CEHR will show a health summary which contains an individual's index, demographic details, medical conditions, drugs, and allergies. It will also provide a search engine for accessing a variety of personal health information such as laboratory results, prescriptions, and referrals (Morrison, Robertson, Cresswell, Crowe, \& Sheikh, 2011; Rudd, Swan, \& Roxon, 2010).

In summary, a PCHR is considered distinct from an EHR; however there is a greater perceived value in connecting them together. PCHR has received considerable interest and investment in New Zealand and overseas recently, however, the adoption rates have been low. Furthermore, the benefits and the barriers of adopting PCHRs were explored vastly in the literature, despite the fact that the clinical evidence of these benefits and barriers remain limited. Moreover, the literature has stressed the value of PCHRs for chronic disease populations and has seen them as being the best users for it.

\section{Methodology}

Research methodology is usually determined by the aim of the study, the nature of the problem and the setting (Berg, 2004). Thus, some problems require qualitative methods while other may be best addressed with quantitative methods. Qualitative research methods are ideal for exploratory and descriptive studies. Quantitative methods are well suited for explanatory studies that collect numerical and quantified data (Schutt, 2016). Given that this research is mostly descriptive and aimed at exploring and gaining insights through inquiry as opposed to statistical analysis, a qualitative approach was appropriate. While there are various qualitative approaches, key informant interviews thought to be more suitable to achieve the aim of the current study. A qualitative approach using key informant interviews will allow direct interaction between the researcher and the informants to create rich data (Hughes, 2002). Interviews were conducted on three different groups to see different views from different 
perspectives. It was important to seek new ideas and information from different groups/experiences.

Sixteen people were interviewed about The Diary (PCHR) from three different groups of users. The sample could not be any larger not only due to the fact that The Diary is a new novel application that not many have used locally but also because of the time limitation when this study was undertaken.

The Diary is an innovative online PCHR which will be used as a live example for this study. By the time the interviews were conducted, The Diary was a beta incomplete version. It was also a stand-alone system that is not connected to any other healthcare system. The Diary collects data such as lifestyle data, medication, symptoms and health conditions and repurposes them onto a single summary page with a graph of the user's progress over their lifetime. The Diary is owned by the patient/client with data uploaded by them. However, family members and other trusted caregivers may also upload data on patients' behalf as appropriate. Patients control who to share data with and they are able to invite their doctors or other healthcare professionals to their diary by email. Patients can allow the invited people to either have read-only access or to be able to edit their Diary. The data then is colour coded to show where it came from and who entered it. This will allow health professionals to evaluate data accordingly. The Diary is also accessible from anywhere at any time as long as there is a device with an internet connection.

The selection criterion of interviewees was based on those who have used The Diary; five people from the company provided The Diary (Group One: The Diary provider), seven from the community organizations that have used The Diary (Group Two: Community Health Workers), and four clients who have used The Diary to manage their own health (Group Three: Clients/Patients). All people who have used The Diary from both of Group One and Two have participated in the interviews, which resulted in variations in numbers from each group. Only Group Three could have included a larger number of participants but unfortunately only four clients have agreed to participate for reasons which will be explained in the Limitation section later on. The interviews lasted 30 minutes on average and were recorded to achieve validity and comprehensiveness (Patton, 2001).

In-depth interviews about The Diary (PCHR) were conducted with sixteen people from three different groups of users in the City of Dunedin /New Zealand. Interview structure and predeveloped themes were also prepared based on the literature review which was sent to the participant prior to the interview (Table 4). Thematic analysis has been used widely in qualitative research and it can be used across a range of epistemology and research questions (King, 2004; Miah \& Genemo, 2016). While there is no clear agreement about how rigorous a thematic analysis is, King (2004), suggested that direct quotes from participants to be embedded within the analytic narratives support the validity of the identified themes and merit of the analysis. Extracts of raw data not only can produce trustworthiness of the identified themes but also insightful findings (Braun \& Clarke, 2006).

The interviews were recorded and transcribed. Coding and detailed analysis using Thematic Content Analysis for the conducted key informant interviews were guided by the seven themes Table 4 . Shows the themes and the interview guiding questions for each group. 


\section{Results and Analysis}

Analysing the data that has been collected through the key informant interviews using thematic analysis

\subsection{Theme One: Workflow and Efficiency}

This theme examined the opinions of the sixteen key informant interview participants regarding their current workflow and how The Diary could improve efficiency. Opinions were examined among the three different groups of participants.

Participants from the group of The Diary provider each identified different characteristics of The Diary that distinguish it from a normal caregiver-controlled system or electronic health records (EHRs).

"...it is owned by the patient; patients can enter their own information which they can't usually do with EHR"

"The Diary captures medical, health and wellness info, temporarily correlates with it and longitudinally displays, which gives caregivers clear picture of a patient's history"

"The Diary repurposes health, medical and wellness data and turns it into knowledge via easyto-understand graphical display".

They also identified problems that The Diary has strong potential in solving. Some participants felt that The Diary would give patients access to their health information, and improve communication and information sharing between patients and their caregivers or clinicians. It enables health workers to access health information of their patients, and improves the family engagement with a patients' health information. It also would empower patients and engage them better with their own health. Moreover, it has the potential to solve the problem of "lack of health and medical data on a patient in a community setting".

The Diary enhances the memory of a patient, as they cannot remember everything during their short visits to the doctor. Patients can enter information whenever they remember, and caregivers can keep track of them as well.

Another problem The Diary would solve is the difficulty of displaying a large amount of health data. The Diary transforms raw data into meaningful information, and uses graphs and tables to summarize and present data.

Moreover, it breaks the traditional doctor-centric medical system. It solves the problem for people with chronic illnesses who need to be in touch with their caregivers on a daily basis, and who usually suffer from lifelong diseases such as diabetes, high cholesterol, or obesity. The Diary may help with these issues, because it;

"...Provides a more balanced picture in the community for lifestyle and for the progress that the patient is making in between the visit to the doctor and the hospital. Also, the information entered by the patient helps the doctor to diagnose them better." 


\begin{tabular}{|c|c|c|c|c|}
\hline$\#$ & Theme & The Diary provider & Community health workers & Patients/clients \\
\hline 1 & $\begin{array}{l}\text { Workflow and } \\
\text { efficiency }\end{array}$ & $\begin{array}{l}\text { 1. What makes The Diary different } \\
\text { than a normal electronic health } \\
\text { record (EHR)? } \\
\text { 2. Problems or needs that The Diary } \\
\text { solves or meets }\end{array}$ & $\begin{array}{l}\text { 1. How patients' information is } \\
\text { currently stored } \\
\text { 2. Needs that attracted community } \\
\text { health workers to The Diary } \\
\text { 3. Community health workers' } \\
\text { expectations for The Diary and the } \\
\text { problems they expected it to solve }\end{array}$ & $\begin{array}{l}\text { 1. Clients' accessibility and desire to } \\
\text { have more access to their health } \\
\text { information and needs that pushed } \\
\text { them to try The Diary Clients' } \\
\text { expectations of The Diary }\end{array}$ \\
\hline 2 & $\begin{array}{l}\text { Usefulness/ } \\
\text { advantages/ } \\
\text { disadvantages }\end{array}$ & $\begin{array}{l}\text { 1. The Diary's impact on healthcare } \\
\text { delivery } \\
\text { 2. The advantages of using The } \\
\text { Diary to manage patients' health } \\
\text { 3. The disadvantages of using The } \\
\text { Diary to manage patients' health }\end{array}$ & $\begin{array}{l}\text { 1. Did The Diary meet community health } \\
\text { workers expectations? } \\
\text { 2. The Diary's role in improving } \\
\text { healthcare delivery } \\
\text { 3. The advantages of using The Diary to } \\
\text { manage patients' health } \\
\text { 4. Disadvantages of The Diary }\end{array}$ & $\begin{array}{l}\text { 1. Advantages and disadvantages of The } \\
\text { Diary for clients }\end{array}$ \\
\hline 3 & $\begin{array}{l}\text { Early adopters/ } \\
\text { innovativeness }\end{array}$ & $\begin{array}{l}\text { 1. The New Zealand market and } \\
\text { where it is heading }\end{array}$ & $\begin{array}{l}\text { 1. Community health workers' attitude } \\
\text { towards trying out new products in } \\
\text { general } \\
\text { 2. Community health workers' } \\
\text { motivations to consider The Diary } \\
\text { 3. Clients' characteristics and } \\
\text { motivation from the perspective of } \\
\text { their community health workers }\end{array}$ & $\begin{array}{l}\text { 1. Clients' motivations to use The Diary } \\
\text { and attitudes in term of trying out } \\
\text { new products }\end{array}$ \\
\hline 4 & Chronic diseases & $\begin{array}{l}\text { 1. The niche markets for The Diary } \\
\text { and characteristics of person who } \\
\text { would most benefit from it. }\end{array}$ & $\begin{array}{l}\text { 1. Characteristics of clients that would } \\
\text { most benefit from The Diary from } \\
\text { community health workers' point of } \\
\text { views }\end{array}$ & $\begin{array}{l}\text { 1. Characteristics of the person that } \\
\text { would most benefit from using The } \\
\text { Diary from the clients' perspective }\end{array}$ \\
\hline 5 & $\begin{array}{l}\text { Security and } \\
\text { privacy }\end{array}$ & $\begin{array}{l}\text { 1. Community groups' general } \\
\text { attitude toward using The Diary, } \\
\text { privacy and security concerns, } \\
\text { and any other concerns from The } \\
\text { Diary provider's participants' } \\
\text { points of views. }\end{array}$ & $\begin{array}{l}\text { 1. Patients' general attitudes toward and } \\
\text { concerns about The Diary from } \\
\text { community health workers' points of } \\
\text { view }\end{array}$ & \\
\hline
\end{tabular}




\begin{tabular}{|c|c|c|c|c|}
\hline$\#$ & Theme & The Diary provider & Community health workers & Patients/clients \\
\hline 6 & Interoperability & $\begin{array}{l}\text { 1. Is integrating The Diary with an } \\
\text { EHR going to produce better } \\
\text { results from the perspective of } \\
\text { The Diary provider? }\end{array}$ & $\begin{array}{l}\text { 1. Is integrating The Diary with EHR } \\
\text { going to produce better results from } \\
\text { the perspective of community health } \\
\text { workers? }\end{array}$ & $\begin{array}{l}\text { 1. Is integrating The Diary with EHRs } \\
\text { going to produce better results from } \\
\text { the perspective of clients? }\end{array}$ \\
\hline 7 & $\begin{array}{l}\text { Improvements/ } \\
\text { usability/ } \\
\text { recommendations }\end{array}$ & $\begin{array}{l}\text { 1. The overall impression of the } \\
\text { community groups' workers } \\
\text { about The Diary from The Diary } \\
\text { provider's points of views }\end{array}$ & $\begin{array}{l}\text { 1. Community health workers' overall } \\
\text { impression of The Diary and any other } \\
\text { concerns } \\
\text { 2. Recommendations to make The Diary } \\
\text { better from community health } \\
\text { workers' perspective } \\
\text { 3. Would community health workers } \\
\text { recommend The Diary for other } \\
\text { community organizations? }\end{array}$ & $\begin{array}{l}\text { 1. Clients' overall impression of The } \\
\text { Diary }\end{array}$ \\
\hline
\end{tabular}

Table 4: Major Themes and the interview guiding questions for each group 
Another problem The Diary has overcome is the ability to solve (which was pointed out by participants) the problem of communication among caregivers or clinicians. The Diary puts them all on the same page and improves the sharing of health data between them, which means they could all work together toward better health for the patients. They believe that The Diary connects desperate data silos across all layers of healthcare.

The second group; a number of community health workers, all confirmed that they normally keep their patients' health information electronic. Only a few indicated that they use paper systems besides the electronic one. Interviewees from this group also identified the needs that made them consider something such as The Diary. This is due to the fact that the patients whom the community organization is serving are hard to deal with, as one participant stated:

"We were not sure about doing that at first because we have hard enough time getting our own clients to engage with us. But I still wanted to use it because it has a lot of potential for the future, but it is not able to be used for our own agency's clients at the moment."

Another interesting point was raised by one of the participants, who believed in the existence of inequalities in health and looked at The Diary as a tool that could reduce such inequalities and gaps in health.

"I believe there have been massive gaps between the health of people with mental illnesses and intellectual disabilities, and the health management IT. As a woman if you have a mental illness you will die 8 years earlier than a woman that doesn't have a mental illness in NZ. As a male if I have a mental illness, I'll die 15 years earlier than somebody who doesn't have a mental illness."

They finally identified the desired outcomes they expected from The Diary. Many participants believed in The Diary as a tool that could help clients to analyse their lifestyle, empower patients to manage their own health information, show greater interest in their own health, and help them with their health behaviour especially, their physical health:

"The Diary is a tool that could help patients realizing themselves and their habits"

One participant believed that it is a useful tool for staff such as support workers to use on behalf of the patients. This is "because some people are quite apathetic about their health". This participant also expected a few proactive clients to take control and be able to fill in The Diary without the need for support. Some of these potential outcomes include:

- $\quad$ Patients ability to manage their own health

- $\quad$ Caregivers ability to track individual's health development

- $\quad$ Patients are helped to become more aware of themselves

- Patients financial problems are solved

- $\quad$ Patients and especially mental illness patients are enhanced to become aware of their physical and mental health status.

- $\quad$ Patients are potentially encouraged to self-manage and show greater interest in their own health.

- Could reduce inequalities and gaps in health. 
The third group, clients/patients were interviewed showed their level of excitement about having more access to their health information. Levels of excitement differed from one client to another; some were keen, and some were not interested at all. Then, they were asked about their expectations of The Diary. Almost all participating clients did not have any expectations of The Diary, they were all bored on the day that they tried it, and all wanted to do a new activity.

"No expectations really, just something different to do that day"

The general impression from clients was that they had been asked to use The Diary from their health workers. Some of the participating clients did not seem to have any basic knowledge about what the role of The Diary in improving their health is.

\subsection{Theme Two: Usefulness/Advantages and Disadvantages}

This theme examined the opinions of the sixteen key informant interviewees regarding the advantages that The Diary could offer, as well as any disadvantages that may impact users.

All participants have identified various advantages that The Diary has strong potentiality in delivering better health outcomes. A few disadvantages were also identified by some of the interviewees.

Participants from The Diary provider's group all agreed strongly that The Diary improves healthcare delivery. For one, The Diary joins fragmented health data and puts it all in one central place. Therefore, it saves clinicians' and caregivers' time and provides them with the information they need in a shorter amount of time, requiring less effort. It also enhances communication between patients and their caregivers; it puts them all on the same page, and helps them understand each other's needs:

"It can improve healthcare delivery by making siloed data more accessible and useful"

"By joining disparate data silos and improving communication among all the members of a $M D C T "$

Participants from this group stressed the value of joining all health information in one place; this unique feature helps health professionals make better clinical decisions and helps patients get involved in decision making:

"In terms of healthcare delivery that better background allows the healthcare team to make better decisions with more comprehensive information".

They also listed many potential advantages that The Diary provides. Some of these potential advantages and ways of improving health delivery were:

- $\quad$ Saving the time of clinicians or caregivers

- $\quad$ Enhancing communications between patients and their caregiver

- $\quad$ Enhancing self-management and empowerment

- $\quad$ Helping health professionals to make better clinical decisions

- Helping patients to take part of the decisions making.

- $\quad$ Providing more comprehensive background of patients 
- $\quad$ Allowing better diagnosis for patients, maybe better health outcomes at lower costs

- Having access from anywhere at any time

In addition, this group of participants also recognized usability issues to be the main barrier for The Diary. They also felt that the disadvantages of The Diary in general include the amount of time taken to fill it in, and the motivation of either caregivers or patients themselves, this is a disadvantage not only for The Diary in particular but also for any other PCHR/Diary.

"Yes, it requires a lot of data to be gathered and, unless much of that can be automated, many users will not bother with it"

As for the community health worker, The Diary did not meet most of their expectations, as they stated below:

"No, it didn't meet my expectations. However, I still see a lot of potential for it in the future".

"I found it very hard to use. The current form that it is in is frustrating".

"No it did not, unfortunately. I'm looking forward to seeing the improved version of the app though".

"No not really".

For the majority of this group of participants, one major problem was the difficulty of engaging their patients with The Diary. The reason for this difficulty was not only because of the usability issues but also because of the clients and the community health workers themselves. Participants felt that The Diary interfered with their relationship with their patients, as they spend so much time showing them how to use The Diary rather than talking about the patients' health. Also, getting patients to work with The Diary was very hard which is:

"Because we work with such a high need population of people that is already hard to engage in itself, so the engagement needs to occur with us"

Although The Diary only delivered a few real advantages for some of the community health worker interviewees, they all believed that it has strong potential in delivering many advantages in the future, such as; encouraging people to improve their health status, helping them understand their health status and educate them on how to improve it, helping the clients' to become independent and self-managed, and improving patients' relationship with their health professionals. Yet, this group of participants (community health workers), also believed that The Diary could not be beneficial and may actually provide disadvantages rather than advantages for community health patients specifically as follows:

- $\quad$ These clients are usually not self-motivated and not interested in improving their health.

- $\quad$ They usually rely on their health professionals and are not proactive at all.

- $\quad$ They are hard to work with and do not engage with their health; their health professionals struggle in making them attend meetings or appointments.

- Most clients of community organizations do not have computer literacy.

- Most of them are low socio economic which means they are usually not able to afford computers, internet or even cell phones. 
- $\quad$ Put an extra load on health professionals and could interfere negatively with the relationship rather than positively.

The third group clients/patients generally did not understand what benefits The Diary could offer for them, they did not have enough education about it and about the advantages they might achieve from using it. Most of the clients were asked to use it by their support workers and did it as a result of boredom or in order to get the free GP voucher. At the same time, some other patients were interested in computers and willing to learn more and that is what attracted them to The Diary. So, having the correct motivation to use The Diary or PCHR is important for update and sustainability.

\subsection{Theme Three: Early Adopters and Innovators}

This theme observed the different personalities of each interviewee. It examined the connections between using The Diary and being an early adopter or an innovator.

The first group of participants shared their opinions on the New Zealand market's direction and whether it is heading toward tools such as The Diary. All interviewees from this group believed that New Zealand is heading in the same direction as The Diary, toward patientcentric and integrated systems.

"The National Health IT board of New Zealand has three priorities for health during the next 10 years, and the first one is making data standardized, the second one is making the data shared, and the third objective is having a patient- centric health record for every New Zealander in $2014 "$.

"The national health IT board has stated that they want to have a patient portal in 2014, which is our Diary if not something similar to it. Everyone in New Zealand will have access to their own health record by then".

"Apps such as this are the first step on the path to a patient portal because they tie together clinicians and support workers but, in the long run, the patient will become in control of their own health".

Whilst the second group of interviewees described themselves in terms of following innovation and new products. They also expressed their opinions on the clients who tried The Diary and gave descriptions of the personalities of those clients. Community health workers all seemed attracted to using new products and to be the first to use such products. The seven participating community health workers expressed different drivers and motives for their interest in The Diary; some were interested in their own health, some were interested in finding something to improve their patients' health and thought of The Diary as a way of doing so, while others were just interested in new technology and wanted to try anything new.

"100\% open to new ideas and new thinking, especially around technology."

"I'm always curious about new things and always give them a try especially if it enhances my physical or mental health"

"I'm always into using new technology"

The participating community health workers also identified different motives that their clients might have had for using The Diary, the following is a list of these different motives:

- $\quad$ Being proactive about their own health and wanting to learn more about it. 
- $\quad$ Being keen on talking about their health problems.

- $\quad$ Curiosity about computers.

- $\quad$ Free GP voucher

- Interest in doing work with other people and work on projects.

- $\quad$ Being in a good relationship with their support worker.

- $\quad$ Being in a good mood on the day that they were asked to try The Diary.

The last group of interviewees also described their personalities and their motivations to use The Diary. Participating clients had different personalities and motives. Most of them, even the clients who did not participate in the interviews, seemed to have a good relationship with their support workers and that is what mostly got them to give The Diary a try. Some of them also seemed to have an interest in learning more about computers.

"Keen about trying things out"

"I'm interested in new things"

"I'm pretty good, not with everything though it depends"

"I'm okay"

\subsection{Theme Four: Chronic Diseases}

In this theme, the opinions of the sixteen key informant interview participants concerning the type of person who would suit and benefit from using The Diary the most were examined.

Each group of participants were asked different sets of questions to suit their role. All participants from all groups identified the characteristics of the person that is intended to benefit from The Diary the most.

The Diary provider's interviewees identified different niche markets for The Diary and all agreed on that The Diary was not designed for chronic illness patients only, although they are intended to benefit from it the most. As stated by participants below:

"The niche markets at the first instance are those who are costing the health market the most, these people with multi medications, chronic ill people such as diabetics, people who are difficult to manage because they are under a multi care basis, and people with mental health disabilities".

"The niche markets are chronic disease patients in the community, nursing and rest homes, community pharmacies, and community health centres".

Participating community health workers had different opinions on who The Diary could suit; Some believed that The Diary would not suit people who take many medications and have multiple health problems. This is due to the fact that "if those patients were interested in their health in the first place, they would not have got themselves into a mess with their health in the first place". Hence, those patients would not be proactive enough to track their health on the internet.

"I can think of a lot of clients that we have that we didn't suggest The Diary for, because we knew it is hard enough to engage them to even taking their blood sugar or changing their lifestyle". 
Some believed that The Diary could suit mentally ill clients as some of these clients are capable and aware of their own conditions and know how to manage them. On the other hand, mentally ill clients could also experience memory loss which means it is hard for them to remember things in the past or remember logins and passwords; this was the case with most of the mentally ill clients; they struggled with memorising logins and passwords which was part of the reason for them not to come back to The Diary.

In the third group one participating client felt that someone who is familiar with computers would most benefit from The Diary, while another participant felt that anyone could get benefit out of using it. One other participant thought parents suit using The Diary best.

One participant believed that it suits mentally or physically depressed people,

"As The Diary helps you express yourself and have a clearer picture of your body. It puts you in the right path and helps you get better quickly. Sometimes people rely on something (some type of food) and ignore many other things, The Diary makes them realize these things and get more aware".

In conclusion, all participating community health workers, and The Diary provider's believed that The Diary would only suit those who are interested in their own health, self-motivated clients, and those who are really keen on finding a way to improve their health. Some of these people could be those who go to the gymnasium regularly.

Also, something like The Diary would only suit clients who can afford internet and computers at their homes, and who have a level of literacy about computers and internet.

\subsection{Theme Five: Security and Privacy}

In this theme, the privacy and security concerns in general, and attitudes of the sixteen key informant interview participants on The Diary were observed. A moderate level of concern about privacy and security was observed. Yet, the main concern for all participants from all of the groups was the difficulty of using The Diary.

Group One's (The Diary provider) participants reported that $0 \%$ of community health workers showed concerns about privacy and security.

"Those who needed it didn't really care and were happy to share their information, as those patients believed that The Diary was supposed to help them get better"

"The Diary has been greeted with great enthusiasm. Privacy and security issues have been discussed, but have not been one of the larger issues, populating The Diary has been the largest issue".

"Generally, in NZ patients want their data to be shared with their healthcare providers, they believe it is a very good thing to do. Patients usually only need to know that the company is doing everything they could to protect their data, they tend to be more open minded and believe in the benefits of The Diary".

While, Group Two (community health worker) reported that 15\% of patients expressed concerns about privacy and security. Surprisingly, clients were not concerned about privacy and security and their general attitude toward The Diary was positive; as one participant indicated: 
"Those clients have been in the health system for so long, they are used to revealing their health information to their health professionals".

Yet, the problem came after they tried to use The Diary especially if it was on their own. As The Diary was a beta unfinished version and had technical and functional issues, it was easy to put some clients off. Clients also had concerns such as:

- $\quad$ The Diary takes too long to be filled in.

- The Diary uses the medical terminologies for health problems and for medications:

"Frustration around entering their medications; not finding the right name/brand for their medication, or they are not being there".

- The Diary also has limitations on dosage selections; as well as limitations on the selection of minerals and vitamins.

Another significant struggle faced by almost every client especially those with mental illnesses was that it was hard for them to remember their login details, which also put most of them off and made it harder to convince them to come back for The Diary.

One other issue that was raised by one participant is that the clinical team usually has trouble engaging with their clients; they normally have enough difficulty trying to make them turn up to appointments or to convince them to make changes in their lives. Thus, asking clients to work with The Diary was really stressful for the clinical team especially as some of them felt over-protective of their clients and did not want to get them involved in something that they were not confident in, themselves. Another issue that was blocking the way for those clients was that most of them are low socio economic, they do not have internet and computers at home as they do not have enough money to afford them.

"So asking them to come in here (to the agency) to sit alongside us to put data on this website that they don't really care about was just too big for us".

In regard to privacy and security, community health workers generally were comfortable.

"Paper based files are not as safe; they could just sit on someone's desk and anyone could read them, I mean they are supposed to be locked away but when you are working on them, they're not".

Yet, only one participant was worried about the data being used in the wrong way such as feeding insurance companies.

"I don't believe anything that is placed on the internet is secure".

Only $25 \%$ of Group Three (clients/patients) participants themselves were concerned about privacy and security. All participants' clients had good attitudes in general toward The Diary.

"It was good and enjoyable; it was not as overwhelming as I expected it to be. I actually enjoyed doing it".

"Was good"

Surprisingly, three out of four clients did not have any concerns about privacy and security, only one client: 
"Was worried of hacking, I don't think anything on the internet is secure really, anyone can hack into it these days"

No other concerns were raised by clients at all. Only one indicated that she did not have concerns because support workers explained to her that if she did not feel comfortable with something being in The Diary, she would be able to take it out.

\subsection{Theme Six: Interoperability}

The opinion of the sixteen interviewees regarding connecting The Diary with EHR and other health systems was examined in this theme.

In general, participants across the three groups expressed interest in the concept of integrating The Diary with electronic health records. Also, some of them suggested other health systems other than EHRs that The Diary should also have integration with, including the pharmacy system and laboratory results.

The Diary provider's interviewees seemed to have an interest in the idea of integrating their Diary with EHRs and other systems. They all believed that this is how their Diary should look like in the future (integrated with EHRs and other health systems), as this will provide a full source of information for clients and health professionals therefore reducing inconsistencies, time, and cost for both clients and health providers.

Community health providers only know a little about their clients; they only know what patients tell them. Sometimes they have to chase up after doctors to get the necessary information which also does not seem to be an easy thing to do. Therefore, community health workers' interviewees expressed high value in connecting all the health systems together which would help those community organizations have much more information about their clients, and help them in moving forward as one participant indicated:

"We know very little about our community-based clients here"

Some participants emphasised the fact that the biggest challenge with the current form of The Diary is that clients especially those with mental health issues would need help to fill it in; clients need motivation to make The Diary successful. Therefore, participants believed that there is a great reward from integrated system;

"So, for us if their information comes through and goes to their file that would be very useful, but have not said that getting them to actually do it, that is the problem"

Surprisingly, some participants had concerns with The Diary being integrated with other systems. One participant was concerned with privacy and security when any integration happens. Another participant was concerned that the integration could possibly "diminish the feeling of control; the feeling that someone is populating your own Diary". One more participant also concerned that integration might cause confidentiality problems and health professionals might not be comfortable with these community health workers being able to access their records.

"Not a fully integration; because medical records need to have some objectivity and distance, it contains information that the clients should not necessarily be reading".

In the third group, it was hard for the participating clients to understand the idea of integration, therefore, little information was provided from them. Only one participating client seemed to understand the idea, as indicated: 
"Yes, especially if the doctor can write me a prescription every now and then through the internet, which I can print out here at this centre"

\subsection{Theme Seven: Improvements, Usability and Recommendations}

This theme examined the impressions of, and the attitudes towards, The Diary from the sixteen key informant participants.

The Diary provider's group described the impressions of community health workers toward The Diary, whilst, community health workers and clients described their own impressions of it.

From the point of view of The Diary provider's interviewees, community groups expressed good impressions of The Diary. However, they also expressed their frustration with the difficulty of using it.

"They really need it and it can tremendously help them".

"They loved the concept, but had trouble working out how to easily incorporate it in their daily roles".

Yet, at the same time, there was strong agreement from the five of The Diary provider's interviewees that the community groups had a huge amount of difficulty using The Diary. Which is in fact due to usability and design issues; The Diary had a complicated user interface and many functional and technical problems. Another factor which made The Diary difficult was indicated to by a few participants:

"There was too much manual data entry, and they had trouble engaging some patients. The benefits were too far in the future".

"Especially because most of the patients don't have computer basics, don't have email addresses, very frustrating"

Also, as The Diary is still a new trend which has no statistics to prove the benefits of it, it is hard to convince new community groups to use it. For The Diary to be a success, especially with community groups, as agreed by all participants, The Diary needs ease of usability at first. One participant suggested touch screens as they are easier to control.

Community health workers participants' almost all expressed a good attitude toward The Diary; they believed that it had various potential benefits. However, it needs time, improvements, and both clients and health workers to buy-in and find motivation for it to be a success. Participants recommended different ideas that might help with improving the adoption of The Diary:

"If it needs to be more successful here, more support workers need to be involved ensuring that their clients are here on a regular basis to update their information. There are more than 50 clients here every day, and we are only 2 support workers".

"It needs to have a lot of support behind it, such as political support from the wider health sector, things like support from the PHO,DHB, and national health board"

"As long as clients are aware of confidentiality, and who they should share their information with, the tool is great". 
Also, one of the participants suggested that if The Diary is going to be used by mental health patients then it needs more directions on mental health. It needs to focus on the mood, hearing voices, behaviours and sleeping habits.

Also, participants all strongly insisted that The Diary needs a lot of functional and technical improvements, and the user-interface should be a lot easier to use.

Some participants thought The Diary is a great tool, but it is not for community groups:

"Why they chose us when there are people out there much more into using The Diary than our clients! They could have more people to use that our harder to reach"

One participant believed that The Diary is not going to be successful amongst community groups, although it has great potential.

Almost all community health workers did not have any concerns about The Diary. Only one felt that "security is the main concern, and then the ease of use".

Although, all of these participants seemed to believe that The Diary is a good idea, each one of them had a different point of view on how to help The Diary go forward. The following is a summary of all the different recommendations that were made by interviewees:

- $\quad$ Some believed it could be successful by only improving the user interface and sorting the technical and functional issues.

- $\quad$ Some others recommended that support workers of health givers are the main drivers for the tool. They need to motivate their clients and work closely with them.

- $\quad$ Meanwhile, some others believed that The Diary needs political support such as support from the district health board or the national health board.

- $\quad$ Also, some recommended that if The Diary is going to be used by mental illness clients then it needs more directions on mental health.

- $\quad$ One recommended that The Diary should be used by caregivers on the behalf of the patients to start with.

- $\quad$ "In mental health, you have got limited opportunity to get clients attention, if they give it to you then you have to maximise that opportunity. If you can't deliver what you said you were going to deliver, then you lose people's interest at all".

Last group of interviewees was a group of clients who did not mention many concerns. Only one client mentioned the problem of constantly forgetting the password.

"It is good, but I keep forgetting my password, so I don't get to fill in my information every week".

However, participating Community Health Workers believed that it was a problem for almost every client, and they also found huge difficulty in using computers.

Another client felt that The Diary needs more about mental health. While one other client's main intention of using The Diary was to manage their weight.

In summary, large amounts of data were obtained from interviewees in regard of the main aim of this study. Data was all organized into seven major themes and analysed using a 
thematic qualitative technique as described in the previous section. The results of the sixteen key informant interviews will be discussed in the following section.

\section{Discussion}

This study explored the adoption of PCHRs in the community within three different groups, that is, The Diary provider, Community Health Workers, and Clients.

Results revealed that, participants from the three participating groups all expressed their views from different perspectives. The Diary provider group, looked at The Diary from a service/business provider perspective, therefore, their opinions were more theoretical. While, the second group of participants (Community Health Workers), saw The Diary from a different angle; more real and usable than The Diary provider's and provided more realistic positive and negative opinions. The third group of participants provided mixed views; this is due to different reasons including:

- Clients' lack of understanding of The Diary and its role in improving their health.

- $\quad$ Clients' lack of experience with computers and technology.

- $\quad$ Clients' perception of their health; being passive about it.

- Clients' lower level of education.

Findings of this study must be interpreted carefully given the limitations of participants especially (clients) sample. Although efforts were made to recruit a larger sample of clients to participate, the final sample was small and consisted mainly of people who had only used The Diary few times and only did so because they were asked to by their support workers. In this section the main results are presented, discussed and combined with the scene setting literature.

\subsection{Workflow and Efficiency}

Results show that The Diary has a strong possibility in improving healthcare systems efficiency. Participants, especially those from The Diary provider group have considered The Diary different from a normal EHR. This has been likewise supported by literature, particularly by Hillestad et al. (2005). Participants have also outlined various characteristics that differentiate The Diary from an EHR, all in which have been supported by the literature as summarized in Table 1.

Participants from both of Group One and Group Two reported several problems with the current healthcare systems that The Diary will possibly solve. One major issue with current healthcare systems and with community health providers in particular is that they are usually out of the loop. Community health providers are facing difficulty in collecting the necessary data for their patients. It also uses up a lot of time and resources. Therefore, they thought that a patient-centric tool such as The Diary will not only solve the breakdown between primary and secondary care, but will also keep community providers informed and in the loop about their patients' health. This is in line with what Coiera (2006) has also reported.

Participants emphasised on the importance of The Diary in improving communication among MDCT. The Diary improves communications among MDCT and provides real time access to patients' information. It captures extra information from the community and from all different 
caregivers and creates a more comprehensive record of patients. This allows all MDCTs to work together toward better health outcomes and improve the sharing of information among them. This is one of the significant differences between The Diary and a normal EHR. This solves the problem for chronic ill patients particularly as they need to be in touch with their caregivers on a daily basis. This has been likewise emphasised by Fichman et al. (2011).

Participants have also reported many different other problems within current healthcare systems that The Diary is expected to solve. They thought that The Diary will engage patients with their health and will make them more aware of their health problems. The Diary also is expected to encourage patients to self-manage their health and show greater interest in their health. It also empowers them and gives them control. These finding have also been discussed within the literature as shown in Table 2.

However, looking at The Diary more practically, Community Health Workers participants thought that The Diary would actually increase their work load. This is due to clients' lack of experience with technology and their need of support from community health workers. This echoes the findings from the literature (Archer et al., 2011; Detmer et al., 2008; Patel et al., 2011; Weitzman et al., 2009), in which that healthcare professionals concern about increased responsibility; learning new technology might have been one of the impediments for the adoption of PCHR. Thus, participants stressed the value of integrating The Diary to EHRs and other healthcare systems, as the current form of The Diary requires effort and time from community health workers to spend with clients. The current form of The Diary held little value to the clients and increases workers' work load, as will be discussed in section 5.7.

Surprisingly, results showed that $50 \%$ of participating clients are not willing to have more access to their health information. The small sample of clients seemed to be happy with the current workflow and the limited amount of data that they have access to, as one participating client thought that there was no need to access their own health information while they can ask their doctor. This result indicates that community groups are reliant on their caregivers and healthcare providers, which creates another barrier for The Diary to be used by community groups. This is opposite to what was reported in the literature (Ball et al., 2007; Schoen et al., 2004; Tang et al., 2003).

\subsection{Usefulness/Advantages and Disadvantages}

Results show that in theory, The Diary will possibly improve healthcare delivery and efficiency in various ways including joining forms of fragmented health data all in one place and putting all caregivers on the same page. Participants also spoke of improving health care delivery by providing enough background and more comprehensive information about individuals' health, therefore, clinicians will be more able to diagnose, assess, and make better decisions regarding patients' health. The Diary also improves communication between clinicians and patients and puts them on the same page. These results in line with previous studies are summarized on (Table 2).

Yet, again when considering The Diary on a more theoretical level, participants across the three different groups identified several advantages that The Diary has strong potentiality in delivering, all of what was supported by the literature. Participants saw The Diary as being able to save time and cost; clinicians have all the information they need at one place and duplication such as blood test duplications are avoided. This result has been likewise supported in many other findings in the literature (Heather et al., 2011; D. C. Kaelber et al., 
2008; D. Kaelber \& Pan, 2008; Steinbrook, 2008). For participants, The Diary enhances the memory of the patients as it helps them remember things they would not normally be able to remember in an interview situation, this is also supported by (Maeder \& Martin-sanchez, 2012). The Diary enhances patients' self-management, empowers them, and gets them involved in decision making, which is also in line with the literature (Ball et al., 2007; Fuji et al., 2012). All of these perceived advantages are consistent with those previously reported in the literature (Table 2).

On the other hand, participants across three groups have also identified several disadvantages of using The Diary. First of which is the difficulty of using the beta-version of The Diary. $80 \%$ of Group One's participants agreed that usability issues are the biggest impediments for the diffusion of The Diary. Also, almost all of Group Two and Group Three participants' have listed the difficulty of using The Diary as the biggest disadvantage.

A second disadvantage of The Diary is the time it takes to be manually populated. This issue has been likewise reported in literature as one of the barriers to adopting PCHR "technical issues" (Kahn et al., 2009; Pagliari et al., 2007). Participants especially those from Group Two felt that The Diary interferes negatively with their relationship with clients rather than positively. This is particularly because patients who belong to community organizations are unlikely to be able to use The Diary by themselves. They are also not proactive about their health and tend to rely so much on their health providers which puts an extra load of work on health workers. This issue has also been highlighted by other studies within the literature (Archer et al., 2011; Detmer et al., 2008; Patel et al., 2011; Weitzman et al., 2009).

While Emont (2011), suggested that PCHR would best suit people with low income, findings from this project suggest the opposite. Results from this project are inline more with other studies which suggested "digital divide" to be one of the barriers for adopting PCHR (Archer et al., 2011; Detmer et al., 2008; Kim et al., 2009; Miah et al., 2017; Patel et al., 2011; Roblin et al., 2009; Sciadas, 2002). Individuals with low income usually cannot afford computers or internet at their own homes. Participants insisted that clients, who belong to community organization lack computer literacy, are low socio economic who cannot afford computers at their own homes. Therefore, they suggested that The Diary would suit someone who is familiar with computers and who at least can afford them at home. Clients' prior experience with technology and their motivation about their health will always play a big role in determining their individual perception of The Diary or any similar patient-centric tool.

A potential disadvantage of The Diary that was not previously identified in the literature was that when patients especially those with chronic or mental illnesses have access to their records. They may begin to realize their bad health habits and their health issues which might affect them negatively and make them depressed rather than helping them move forward.

Another disadvantage of The Diary that was not discussed in the literature is that The Diary uses medical terminology for medication and health problems. Clients usually do not know the medical terms for their conditions or medications and that was one of the reasons to put them off.

\subsection{Early Adopters and Innovators}

The Diary provider emphasised that New Zealand is heading in the same direction as The Diary, and that was the main reason for The Diary to be created in a place like New Zealand. This is the main motive for The Diary provider group. It also appeared that some of the 
community health workers, especially those who had a managerial role, recognized the importance of The Diary in New Zealand and the government plans on launching client portals in 2014. Therefore, this project is particularly timely and could provide valuable results especially in New Zealand.

In terms of who they envisioned as early adopters of The Diary, participants seemed to believe it would be clients who are interested in their health and who are looking for new ways to improve their health regardless of their health conditions. Moreover, despite the fact that The Diary is potentially more beneficial to clients with chronic diseases, participants suggested that only motivated clients and community health workers might be more likely to use it, as will be discussed in the next section.

Weitzman et al., (2009) suggested that the age of the user may affect their attitudes towards PCHRs. However, referring to results, it appeared that the age was not a significant factor in determining early adopters. On the other hand, digital divide such as social status and users' level of education acted as important factors on their attitude toward The Diary. Most of participating clients had only a secondary school level of education and had no access to the internet from their own homes. This result is in line with results from other studies (Archer et al., 2011; Detmer et al., 2008; Patel et al., 2011; Roblin et al., 2009; Sciadas, 2002).

One of the important findings is that motivation from both patients and health workers is the main aspect for The Diary to work with community groups. Health workers themselves need to support and educate their patients about The Diary and get them to use it on a regular basis. It appeared that most of the clients used The Diary without having a basic understanding of how it might help them improve their health.

\subsection{Chronic Diseases}

Patient-centred approaches are expected to facilitate care coordination among patients with chronic illnesses who usually receive their care from a number of different healthcare providers and caregivers (DiMarco et al., 2009; Pagliari et al., 2007; Steinbrook, 2008). However, findings show that The Diary is best for those who have different caregivers and who take many medications only in theory and ideally. Participants believed that The Diary can help these types of patients ONLY if they were interested in doing so. Patients' buy-in and motivation is the main key for The Diary to be useful for clients with long term conditions. The Diary would perfectly suit people who are trying to make a difference in their life and are looking for something to help them manage their health such as those who attend the gym on a regular basis. Results show that The Diary would work perfectly for any client who is interested in their health regardless of their age or health status.

Also, participants identified the niche market for The Diary as clients who can afford computers and internet, and who have a level of literacy about technology (knows how to use computers).

In addition, findings show that The Diary has a larger potential to suit caregivers and those who are caring for others with chronic illnesses than patients who themselves have chronic illnesses. The Diary could be more beneficial for clinicians and caregivers themselves to be on the same page. It collects all the fragmented health data in one place for clinicians, which would reduce the time they need to spend on it and the effort they need to put in as well as offering comprehensive records for patients, helping them in decision making. This finding had also been emphasised in other findings in the literature (Caligtan \& Dykes, 2011; Pagliari et al., 2007; Tang et al., 2006; Wunder, 2009). 
Furthermore, some participants believed that The Diary could suit mentally ill clients as some of these clients are capable and aware of their own conditions. On the other hand, some others believed mentally ill clients could also experience memory loss which means it is hard for them to remember things in the past such as logins and passwords. In fact, this was the case with most of the clients; they struggled with memorising logins and passwords. Moreover, those patients will most likely require assistance while working on The Diary which will increase the workload of their health workers as discussed earlier.

\subsection{Security and Privacy}

What was striking was that participants did not express many concerns with respects to security and privacy. Only one community health worker believed that nothing on the internet is secure. However, all other participants simultaneously believed that these issues could easily be overcome, and are not initiating an issue nowadays; as evidenced of their point, they used the examples of online banking and the fact that paper records could also be affected by malicious access. Also, as The Diary complies with New Zealand's regulations, community groups especially on the management level were more confident with it. This is opposite to Detmer et al. (2008)'s findings. On the other hand, in line with findings from (Walker et al., 2009; Weitzman et al., 2009); it appeared that the desire to have a full record of health information in an emergency situation fades away any concerns over privacy and security from those with chronic illnesses.

\subsection{Interoperability}

Participants across the three different groups expressed a high value in integrating all the health systems together. They believed that integrated systems would help those community organizations have much more access to the necessary health information for individuals, which will also reduce cost and effort ultimately. They also believed that if The Diary was integrated to the EHR and to all other health care systems it would have been easier. The Diary as it is a stand-alone takes a lot of time to complete and is an error prone process. This has likewise been emphasised by other studies (Archer et al., 2011; Detmer et al., 2008; Kim et al., 2009; Tang et al., 2006).

Nevertheless, only a small percentage of Community Health Worker participants were concerned with The Diary being integrated to the EHR and that is for different interesting reasons. One of the significant reasons which were not previously discussed in the literature is that when someone else has access to your record. It diminishes the feeling of empowerment and ownership. Also, patients should not know about everything that their health professionals write about them; it could be too revealing and health professionals might not feel comfortable with it.

\subsection{Improvements, Usability and Recommendations}

The current form of The Diary was deemed not user friendly for almost all participants; most of whom were disappointed by the amount and the type of data that they needed to enter themselves. Also, the registration process was laborious, took very long, and was complicated especially for clients.

As well as fixing the technical issues with The Diary and creating a more user-friendly interface, one of the necessary things to accelerate uptake of something like The Diary by community groups would be IT skills training along with providing them with wider access to computers and internet. Another important factor to make The Diary more successful with community 
groups is education. Clients need to understand the anticipated benefits of The Diary and how it might help in improving their health, not only the need to know how to use it.

Moreover, The Diary needs motivation not only from the clients but also from clinicians and support workers. They need to motivate their clients and work closely with them.

Some suggested touch screens, as almost all clients struggled with using the mouse and they keyboard.

\section{Conclusions}

In summary, there was widespread consensus from almost all participants about the potential future value of The Diary. They identified several advantages as well as challenges associated with adopting The Diary. Our key findings suggest that The Diary suits motivated clients such as those who attend the gymnasium regularly despite their health status or age. Also, The Diary suits those who at least have basic knowledge about computers and internet and who can afford them at home. Furthermore, there is a great value in integrating The Diary with EHR and other health-related systems, otherwise The Diary takes up a lot of time and effort and might be an error-prone process.

Furthermore, a number of factors will likely accelerate uptake, more widespread use of patient-centric tools were suggested by participants as discussed in the previous section (5.7). Also, the following is a summary of the current barriers for clients to use The Diary in which need to be considered in future development:

- Cost: community groups are low socio economically who cannot afford computers and internet at their own homes.

- $\quad$ Lack of access: limited number of computers available at the community centre \& having no other place to access the internet from.

- $\quad$ Lack of computer literacy: do not have the computer literacy necessary to be able to use The Diary.

- $\quad$ Typing problems

- $\quad$ Cognitive difficulties

- $\quad$ Community groups are hard people to deal with; health workers have enough trouble trying to get their patients to attend appointments.

- $\quad$ Community groups are usually not interested in improving their health and are not usually self-motivated.

This project had several limitations. For one, the sample size was small in general. This is due to the fact that the topic of this project is a new and innovative area that not only did the literature not have many studies about, but also not many people are using it especially locally.

Although efforts were made to recruit more participants from the third group (Clients/Patients), the sample ended up very small. However, it was not possible to recruit any more participants from the other two groups.

Even though the sample size was small, interviews allowed in-depth conversation with participants unlike a survey and the themes were satiated. 
Another limitation of this study was that The Diary was beta unfinished version. That did not only affect community groups' general attitude toward The Diary, but it also was the reason for many clients to refuse taking part of the interviews. That is for a few reasons including:

- Clients struggled so much with using The Diary and found it extremely hard to use.

- Clients lack computer literacy. They found it hard to take control of the mouse and the keyboard.

- Clients felt that The Diary takes so long to be populated manually.

- Clients lack of education about The Diary and how it might help them.

Although, The Diary was a beta-version it was enough for participants to see how it works as it was almost a completed version. Also, using the beta-version would help the provider to use the end users' comments about The Diary and improve it.

Also, as the results revealed, community clients are not willing to change the way they receive health information and are not looking for new ways to manage their health.

This research could be expanded in the future and new directions could be pursued by:

- $\quad$ Recruiting a larger sample of participants

- $\quad$ Including other MDCT members such as hospital-based clinicians and general practitioners.

- Including more patients with chronic illnesses and not only mentally ill patients

- $\quad$ Including healthy patients

- Using another PCHR system other than The Diary that is fully finished and easier to use.

- $\quad$ Possibly using other data collection methods such as focus groups

\section{References}

Anoshiravani, A., Gaskin, G. L., Wilson, T., Kopetsky, E., Sandborg, C., \& Longhurst, C. A. (2011). Implementing an interoperable personal health record in pediatrics: lessons learned at an academic children's hospital. Journal of Participatory Medicine, 3, e30.

Archer, N., Fevrier-Thomas, U., Lokker, C., McKibbon, K. A., \& Straus, S. E. (2011). Personal health records: a scoping review. Journal of the American Medical Informatics Association, 18(4), 515-522.

Ball, M. J., Carla Smith, N., \& Bakalar, R. S. (2007). Personal health records: empowering consumers. Journal of Healthcare Information Management, 21(1), 77.

Beard, L., Schein, R., Morra, D., Wilson, K., \& Keelan, J. (2012). The challenges in making electronic health records accessible to patients. Journal of the American Medical Informatics Association, 19(1), 116-120.

Berg, Bruce Lawrence. (2004). Qualitative research methods for the social sciences (Vol. 5): Pearson Boston. 
Blake, Jacqueline, \& Kerr, Don. (2010). Development of an Online Sleep Diary for Physician and Patient Use. Knowledge Management E E-Learning: An International Journal, 2(2), 188202.

Bourgeois, F. C., Taylor, P. L., Emans, S. J., Nigrin, D. J., \& Mandl, K. D. (2008). Whose personal control? Creating private, personally controlled health records for pediatric and adolescent patients. Journal of the American Medical Informatics Association, 15(6), 737-743.

Braun, Virginia, \& Clarke, Victoria. (2006). Using thematic analysis in psychology. Qualitative Research in Psychology, 3(2), 77-101. doi: 10.1191/1478088706qp063oa

Caligtan, C. A., \& Dykes, P. C. (2011). Electronic health records and personal health records. Seminars in Oncology Nursing, 27(3), 218-228.

Chen, Catherine, Garrido, Terhilda, Chock, Don, Okawa, Grant, \& Liang, Louise. (2009). The Kaiser Permanente Electronic Health Record: transforming and streamlining modalities of care. Health Affairs, 28(2), 323-333.

Coiera, Enrico. (2006). Communication systems in healthcare. Clinical Biochemist Reviews, 27(2), 89.

Connecting for Health. (2003). The Personal Health Working Group: Final Report: Markle Foundation.

Detmer, D., Bloomrosen, M., Raymond, B., \& Tang, P. (2008). Integrated personal health records: transformative tools for consumer-centric care. BMC Medical Informatics and Decision Making, 8(1), 45.

DiMarco, C., Wiljer, D., \& Hovy, E. (2009). Self-managed access to personalized healthcare through automated generation of tailored health educational materials from electronic health records. Association for the Advancement of Artificial Intelligence, 4-7.

Dimick, Chris. (2008). A Cost-Benefit Model for PHRs. Journal of American Health Information Management Association, AHIMA. .

Emont, S. (2011). Measuring the Impact of Patient Portals: What the Literature Tells Us. California HealthCare Foundation.

Ennis, L., Rose, D., Callard, F., Denis, M., \& Wykes, T. (2011). Rapid Progress or Lengthy Process? Electronic Personal Health Records in Mental Health. BMC Psychiatry, 11(1), 117.

Fichman, Robert G, Kohli, Rajiv, \& Krishnan, Ranjani. (2011). The role of information systems in healthcare: current research and future trends. Information Systems Research, 22(3), 419428.

Fuji, K.T., Abbott, A.A., Galt, K.A., Drincic, A., Kraft, M., \& Kasha, T. (2012). Standalone personal health records in the United States: meeting patient desires. Health and Technology, 2(3), 197-205.

Greenhalgh, T., Hinder, S., Stramer, K., Bratan, T., \& Russell, J. (2010). Adoption, nonadoption, and abandonment of a personal electronic health record: case study of HealthSpace. BMJ: British Medical Journal, 341, 11. 
Heather, C.O'Donnell., Patel, V., Kern, L. M., Barron, Y., Teixeira, P., Dhopeshwarkar, R., \& Kaushal, R. (2011). Healthcare Consumers' Attitudes Towards Physician and Personal Use of Health Information Exchange. Journal of General Internal Medicine 26(9), 1019-1026.

Hiller, J., McMullen, M. S., Chumney, W. M., \& Baumer, D. L. (2011). Privacy and Security in the Implementation of Health Information Technology (Electronic Health Records): US and EU Compared. BUJ SCI. E TECH. L., 17, 1.

Hillestad, R., Bigelow, J., Bower, A., Girosi, F., Meili, R., Scoville, R., \& Taylor, R. (2005). Can electronic medical record systems transform health care? Potential health benefits, savings, and costs. Health Affairs, 24(5), 1103.

Hoerbst, A., Kohl, C.D., Knaup, P., \& Ammenwerth, E. (2010). Attitudes and behaviors related to the introduction of electronic health records among Austrian and German citizens. International Journal of Medical Informatics, 79(2), 81.

Hughes, T.J. (2002). Marketing principles in the application of e-commerce. Qualitative Market Research: An International Journal, 5(4), 252-260.

Kaelber, D. C., Jha, A. K., Johnston, D., Middleton, B., \& Bates, D. W. (2008). A research agenda for personal health records (PHRs). Journal of the American Medical Informatics Association, 15(6), 729-736.

Kaelber, D., \& Pan, E.C. (2008). The value of personal health record (PHR) systems. AMIA Annual Symposium Proceedings, 2008, 343-347.

Kahn, J.S., Aulakh, V., \& Bosworth, A. (2009). What it takes: characteristics of the ideal personal health record. Health Affairs, 28(2), 369-376.

Keselman, A., Slaughter, L., Arnott-Smith, C., Kim, H., Divita, G., Browne, A., . . Z ZengTreitler, Q. (2007). Towards consumer-friendly PHRs: patients' experience with reviewing their health records. American Medical Informatics Association, 2007, 399-403.

Kim, E. H., Stolyar, A., Lober, W. B., Herbaugh, A. L., Shinstrom, S. E., Zierler, B. K., . . Kim, Y. (2009). Challenges to using an electronic personal health record by a low-income elderly population. Journal of Medical Internet Research, 11(4).

King, Nigel (Ed.). (2004). Using templates in the thematic analysis of text: SAGE Publications.

Krist, A. H., \& Woolf, S. H. (2011). A vision for patient-centered health information systems. JAMA: The Journal of the American Medical Association, 305(3), 300.

Lafky, DB, \& Horan, TA. (2008). Health Status and Prospective PHR Use. AMIA Annual Symposium Proceedings, 1016.

Levinson, Wendy, Lesser, Cara S, \& Epstein, Ronald M. (2010). Developing physician communication skills for patient-centered care. Health Affairs, 29(7), 1310-1318.

Lober, W. B., Zierler, B., Herbaugh, A., Shinstrom, S. E., Stolyar, A., Kim, E. H., \& Kim, Y. (2006). Barriers to the use of a personal health record by an elderly population. AMIA Anпu Symp Proc., 2006, 514-518.

Maeder, A.J., \& Martin-sanchez, FJ. (2012). Health Informatics: Building a Healthcare Future Through Trusted Information-Selected Papers from the 20th Australian National Health Informatics Conference (Hic 2012) (F. J. M.-S. Anthony J. Maeder Ed. Vol. 178): Ios PressInc. 
Mandl, K. D., Simons, W. W., Crawford, W. C. R., \& Abbett, J. M. (2007). Indivo: a personally controlled health record for health information exchange and communication. BMC Medical Informatics and Decision Making, 7(1), 25.

Miah, Shah Jahan, \& Genemo, Hussein. (2016). A Design Science Research Methodology for Expert Systems Development. 2016, 20. doi: 10.3127/ajis.v20i0.1329

Miah, Shah Jahan, Hasan, Najmul, Hasan, Rashadul, \& Gammack, John. (2017). Healthcare support for underserved communities using a mobile social media platform. Information Systems, 66, 1-12. doi: https://doi.org/10.1016/j.is.2017.01.001

Morrison, Z., Robertson, A., Cresswell, K., Crowe, S., \& Sheikh, A. (2011). Understanding contrasting approaches to nationwide implementations of electronic health record systems: England, the USA and Australia. Journal of Healthcare Engineering, 2(1), 25-42.

Pagliari, C., Detmer, D., \& Singleton, P. (2007). Potential of electronic personal health records. BMJ: British Medical Journal, 335(7615), 330.

Patel, V. N., Abramson, E., Edwards, A. M., Cheung, M. A., Dhopeshwarkar, R. V., \& Kaushal, R. (2011). Consumer attitudes toward personal health records in a beacon community. The American journal of managed care, 17(4), e104.

Patton, M.Q. (2001). Qualitative research \& evaluation methods (M. Q. Patton Ed. 3, illustrated, reprint ed.): Sage Publications, Incorporated.

Pyper, C., Amery, J., Watson, M., \& Crook, C. (2004). Patients' experiences when accessing their on-line electronic patient records in primary care. The British Journal of General Practice, 54(498), 38.

Roblin, D. W., Houston, T. K., Allison, J. J., Joski, P. J., \& Becker, E. R. (2009). Disparities in use of a personal health record in a managed care organization. Journal of the American Medical Informatics Association, 16(5), 683.

Rudd, K., Swan, W., \& Roxon, N. (2010). A national health and hospitals network for Australia's future - Delivering better health and better hospitals. Australia: Commonwealth of Australia Retrieved from http://www.health.gov.au/internet/yourhealth/publishing.nsf/Content/re port-redbook/\$File/HRT report3.pdf.

Schoen, C., Osborn, R., Huynh, P.T., Doty, M., Davis, K., Zapert, K., \& Peugh, J. (2004). Primary care and health system performance: adults' experiences in five countries. HEALTH AFFAIRS, 23, 283-283.

Schutt, Russell K. (2016). Understanding the social world: Research methods for the 21st century: Sage Publications.

Sciadas, G. (2002). The digital divide in Canada: Science, Innovation and Electronic Information Division, Statistics Canada.

Shaw, N. T., Kulkarni, A., \& Mador, R. L. (2011). Patients and Health Care Providers' Concerns about the Privacy of Electronic Health Records: A Review of the Literature. electronic Journal of Health Informatics, 6(1), e3.

Silvestre, A.L., Sue, V.M., \& Allen, J.Y. (2009). If you build it, will they come? The Kaiser Permanente model of online health care. Health Affairs, 28(2), 334-344. 
Sprague, L. (2006). Personal health records: the people's choice. NHPF Issue Brief, 820, 1-13.

Steinbrook, R. (2008). Personally Controlled Online Health Data-The Next Big Thing in Medical Care? New England Journal of Medicine, 358(16), 1653-1656.

Tang, P. C., Ash, J. S., Bates, D. W., Overhage, J. M., \& Sands, D. Z. (2006). Personal health records: definitions, benefits, and strategies for overcoming barriers to adoption. Journal of the American Medical Informatics Association, 13(2), 121.

Tang, P. C., Black, W., Buchanan, J., Young, C. Y., Hooper, D., Lane, S. R., . . Turnbull, J. R. (2003). PAMFOnline: integrating EHealth with an electronic medical record system.

Tenforde, M., Jain, A., \& Hickner, J. (2011). The Value of Personal Health Records for Chronic Disease Management: What Do We Know? Family Medicine, 43(5), 351-354.

Tomlinson, M., Swartz, L., Officer, A., Chan, K. Y., Rudan, I., \& Saxena, S. (2009). Research priorities for health of people with disabilities: an expert opinion exercise. The Lancet, 374(9704), 1857-1862.

Walker, J., Ahern, D.K., Le, L.X., \& Delbanco, T. (2009). Insights for internists:“I want the computer to know who I am". Journal of General Internal Medicine, 24(6), 727-732.

Weitzman, E. R., Kaci, L., \& Mandl, K. D. (2009). Acceptability of a personally controlled health record in a community-based setting: implications for policy and design. Journal of medical Internet research, 11(2).

Wunder, S.S. (2009). Pursuing The Promise Of Patient Portas. Healthcare Financial Management Association.

Wynia, M. K., Torres, G. W., \& Lemieux, J. (2011). Many Physicians Are Willing To Use Patients' Electronic Personal Health Records, But Doctors Differ By Location, Gender, And Practice. Health Affairs, 30(2), 266.

Zickmund, S.L., Hess, R., Bryce, C.L., McTigue, K., Olshansky, E., Fitzgerald, K., \& Fischer, G.S. (2008). Interest in the use of computerized patient portals: role of the providerpatient relationship. Journal of General Internal Medicine, 23, 20-26.

Copyright: @ 2019 Ghandour \& Ghandour. This is an open-access article distributed under the terms of the Creative Commons Attribution-NonCommercial 3.0 Australia License, which permits non-commercial use, distribution, and reproduction in any medium, provided the original author and AJIS are credited.

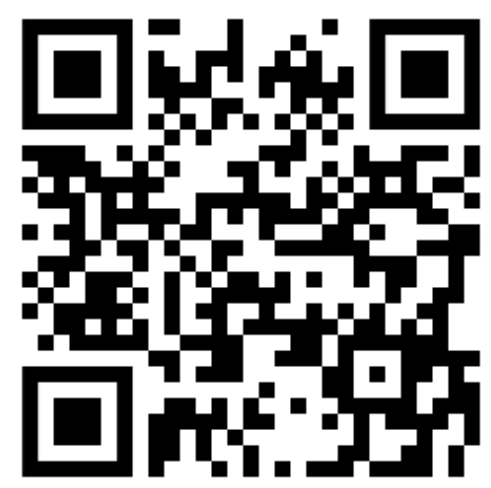

